\title{
Effect of rice husk Biochar (RHB) on some of chemical properties of an acidic soil and the absorption of some nutrients
}

\author{
${ }^{1 *}$ GHORBANI, M; ${ }^{2}$ AMIRAHMADI, E \\ Soil Science, Department of Soil Science, University of Guilan, Rasht, Iran \\ Forestry \& Forest Ecology Sari University of Agricultural Sciences \& Natural Resources Sari, Iran \\ m.ghorbani.7091@gmail.com.amirahmadielnaz@gmail.com
}

\begin{abstract}
The purpose of this study is to evaluate the biochemical effects of rice husk biochar (RHB) obtained from pyrolysis of rice husk under limited oxygen conditions for three hours at temperature of $500{ }^{\circ} \mathrm{C}$. Then, the effect of addition of 2 and $4 \%$ biochar to acidic soil was studied. The samples were stored in greenhouse conditions for three months, and then soil characteristics including $\mathrm{pH}$, electrical conductivity, cation exchange capacity and organic carbon content, potassium forms and total nitrogen content of soil were measured. The results showed that RHB caused a significant increase in soil pH. RHB also increased significantly the organic carbon content and electrical conductivity. Soluble, exchangeable and non-exchangable potassium were affected by the addition of RHB. RHB caused 5-fold increased soluble potassium. The exchange rate of potassium increased from 76 $\mathrm{mg} / \mathrm{kg}$, with a RHB of $2 \%$ to $112 \mathrm{mg} / \mathrm{kg}$ with a $4 \%$ RHB application. Non- exchangable potassium also increased from 290 in control to $532 \mathrm{mg} / \mathrm{kg}$ in $4 \%$ RHB. The usability of nitrogen and phosphorus was not affected by biochar. Considering the significant increase in the amounts of different forms of potassium and considering the lack of potassium in some acidic soils of Mazandaran province, we can consider the use of biochar as a source of potassium in soil fertility management.
\end{abstract}

DOI: https://dx.doi.org/10.4314/jasem.v22i3.4

Copyright: Copyright (C) 2018 Ghorbani et al. This is an open access article distributed under the Creative Commons Attribution License (CCL), which permits unrestricted use, distribution, and reproduction in any medium, provided the original work is properly cited.

Dates: Received: 02 January 2018; Revised: 24 February: 2018; Accepted: 20 March 201

Keywords: pH of soil, cation exchange capacity, potassium

\footnotetext{
* Corresponding author Email: m.ghorbani.7091@ gmail.com
} 
Biochar is the result of the pyrolysis of organic compounds. Pyrolysis of organic compounds such as crop and forest residues in low oxygen and no oxygen conditions and high temperatures causes some volatile carbon compounds as well as some residual carbon compounds, and ash contains significant amounts of calcium and potassium (Abdul and Abdul, 2017; Burrel et al., 2016). Today, addition of biochar to soils as a method for sequestration carbon inside the soil and reducing the concentration of carbon dioxide has attracted a lot of attention (Larid et al., 2010; Lehmann and Joseph, 2009). Adding biochar to the soil can be important given the role carbon plays in the chemical, biological and physical processes of the soil. Larid et al. (2010) showed that a significant reduction in the nutrient leaching of nutrients such as nitrogen, phosphorus, magnesium, and silica occurred by Addition of a biochar derived from animal fertilizers to agricultural soils.

Mukherjee et al. (2014) showed a superfluid impact on the elemental cycle and the prevention of carbon leakage, nitrogen and phosphorus in the soil, and stated that biochar had a range of forms of food elements that were released at different rates and they have different effects on soil fertility. Extract output from lumens soils treated with walnut biochar have higher potassium and sodium content and less phosphorus, calcium, magnesium and zinc than the control soil (Ouyang and Zhang, 2013). Biochar from bamboo can also reduce ammonia leaching by $15 \%$ over 70 days (Ding et al., 2010). Although studies have been conducted on the effects of various biochar on the leaching status, the cycle of elements and the amounts of nutrients released to the soil, so far, no study has been done on the effect of rice husk Biochar (RHB) on different types of potassium in soil. High amounts of potassium present in plant debris and the resulting extracts can have a significant effect on the potassium status of soils. Since potassium is one of the most widely used plant elements and its deficiency is common in acid soils, it can be studied as a modifying agent for improving the fertility of potassium in soil. Considering the abundance of rice cultivars in the northern regions of Iran, and due to mismanagement of the land that burns these residues, we used these native wastes to prepare biochar in this study. After that, the effect of RHB on some chemical properties of a lumenny soil collected from fields of Sari University of Agricultural Sciences and Natural Resources in northern Iran was investigated.

\section{MATERIALS AND METHODS}

Soil properties: Soil used was collected from from 0 to 30 centimeters depth in lands under cultivation of the Faculty of Agriculture and Natural Resources of Sari. After air drying of soil samples. They were molded and passed through a $2 \mathrm{~mm}$ sieve. Different physical and chemical tests, including soil particle size distribution (Rowell, 1994), pH, calcium carbonate equivalent, electrical conductivity, cation exchange capacity and organic carbon content (Nelson et al., 1996) on soil samples were examinated. The total nitrogen of the soil was measured by Kjeldahl and available phosphorus by extraction with sodium bicarbonate method was measured (Olsen, 1954). Measurement of different forms of potassium was measured by method of Helmke and Sparks (1996). Soluble potassium in soil saturation extract, exchangeable potassium with ammonium acetate a normal $(\mathrm{pH}=7)$ and potassium non-binder with nitric acid a normal boiling water was measured. The concentration of potassium in the extracts was measured using the Jenway PFP7 Flame Photometer. Non-exchangable potassium was measured by adding nitric acid from ammonium acetate to a potassium fraction. Table 1 shows the physical and chemical properties of the studied soil.

Preparation of biochar: Residues of rice husk Biochar (RHB) used to prepare biochar, collected from the fields of Sari city. The collected residues after air drying were placed in an aluminum can to create limited oxygen availability conditions. The pyrolysis of the samples Was performed in an electric furnace at a temperature of $500{ }^{\circ} \mathrm{C}$ for 3 hours. The temperature increase of the furnace was about 10 degrees Celsius per minute. One day and night, the specimens were allowed to reach the ambient temperature. Then, the percentage of carbon and carbon monoxide was measured by elemental decomposition of the VarioMax $\mathrm{CHO}$ model. Also, $\mathrm{pH}$ values, electrical conductivity and soluble potassium levels were measured in the same way as in the soil. Table 2 indicates the chemical properties of used biochar in this study.

\begin{tabular}{|c|c|c|c|}
\hline Parameter & Amount & Soils elements & Amount \\
\hline Sand $(\%)$ & $26 / 9$ & $\mathrm{~N}\left(\mathrm{mg} \mathrm{kg}^{-1}\right)$ & $0 / 14$ \\
\hline Silt $(\%)$ & $13 / 5$ & $\mathrm{P}\left(\mathrm{mg} \mathrm{kg}^{-1}\right)$ & 41 \\
\hline Clay $(\%)$ & $59 / 6$ & Soluble $\mathrm{K}\left(\mathrm{mg} \mathrm{kg}^{-1}\right)$ & $7 / 7$ \\
\hline Organic matter $(\%)$ & $0 / 46$ & Exchangable $\mathrm{K}\left(\mathrm{mg} \mathrm{kg}^{-1}\right)$ & 73 \\
\hline $\mathrm{pH}(1: 1)$ & $5 / 78$ & Non-Exchangable $\mathrm{K}\left(\mathrm{mg} \mathrm{kg}^{-1}\right)$ & 219 \\
\hline $\mathrm{EC}(\mathrm{dS} / \mathrm{m})$ & $0 / 76$ & & \\
\hline CEC $\left(\mathrm{cmol} . \mathrm{kg}^{-1}\right)$ & $31 / 5$ & & \\
\hline
\end{tabular}

CEC: Cation exchange capacity; EC: Electrical conductivity 
Table 2: Chemical characteristics of RHB

\begin{tabular}{ccccc}
\hline $\mathrm{pH}_{H 2 O}(1: 1)$ & $\mathrm{EC}\left(\mathrm{dSm}^{-1}\right)$ & Carbon $(\%)$ & Molar ratio of $\mathrm{H} / \mathrm{C}$ & Soluble $\mathrm{K}\left(\mathrm{mg} \mathrm{kg}^{-1}\right)$ \\
\hline $9 / 19$ & $0 / 38$ & $49 / 1$ & $0 / 63$ & $19 / 2$ \\
\hline
\end{tabular}

Treatments and incubation: The amounts of $2 \%$ and $4 \%$ RHB were mixed with the soil in three replicates. Soil samples without biochar considered as control. The samples were incubated in plastic pots at a temperature of $25{ }^{\circ} \mathrm{C}$ and moisture content for a period of three months. The moisture content of the field capacity was considered to be half the amount of saturated soil moisture content. The moisture content of the samples was kept at a field capacity level with daily weighing. After the end of the third month, the samples air drying then $\mathrm{pH}$ values, electrical conductivity, cation exchange capacity and organic carbon, different forms of potassium including soluble, exchangeable and non-exchangeable, total nitrogen, phosphorus were measured by explained methods for the initial soil.

Statistic analysis: For statistical analysis of the samples was used SPSS version 24.0 and Duncan's test at 5\% significance level to compare the means.

\section{RESULTS AND DISCUSSION}

RHB Effect on Soil Properties and Usability of Elements: Table 3 shows the variation of soil properties due to the use of RHB. Both levels of RHB application increased significantly soil $\mathrm{pH}$. Liang et al. (2006) also showed a significant increase in soil $\mathrm{pH}$ as a result of biochar application. RHB also significantly increased the electrical conductivity of the soil. Both levels of RHB significantly increased the amount of organic carbon, but the 4\% RHB showed the most effect. So, RHB $2 \%$ increased the soil salinity by $0.16 \mathrm{dS} / \mathrm{m}$ while the increase for RHB $4 \%$ was $0.43 \mathrm{dS} / \mathrm{m}$. It seems that increasing the electrical conductivity associated with the addition of soluble salts, as well as the biochar effect on soil compositions and the release of soluble elements. However, a more detailed study is needed in this regard. The organic carbon content of the soil was also affected by RHB and its application level. but the 4\% RHB showed the most effect. The cation exchange capacity of the soil was not influenced by the biochar application, which agrees with the results of Haefele et al. (2011) and different from the results of Liang et al. (2006), which stated that biochar increases the cation exchange capacity of the soil.

The results of Table 3 also show that RHB significantly increased the amount of nitrogen in soil. Yoo et al. (2014) showed that the use of sewage biochar increased the usability of nitrogen and phosphorus in soil. Of course, Yoo et al. (2014) have shown that the amount of elements in biochar depends on its production temperature, and with increasing production temperatures, the amount of nitrogen is reduced and the amount of elemental compounds is increased. Xu et al. (2013) concluded that after adding biochar to the soil increases the speed of nitrogen deformation in the short term. As a result, the increased nitrogen utilization of the soil is converted into organic compounds by mineralizing organic resistant soil and de-immobilizing nitrogen. Dong et al. (2015) argued that biochars can be released into soil when they are added to the soil and can release significant amounts of elements such as nitrogen and phosphorus.

Soil phosphorus decreased under the influence of RHB application. Mendez et al. (2012) also showed that the use of phosphorus as a result of unsustainable application to sewage sludge was significantly reduced by using sewage sludge and biomass produced from it in an acidic soil. This can be due to the amount of clay and the resulting cation exchange capacity, which is one of the factors influencing the usability of this element (Carvalho et al., 2016).

\begin{tabular}{ccccccc}
\multicolumn{6}{c}{ Table 3: The impact of RHB on some of the soil characteristics and the use of elements } \\
\hline Treatments & $\begin{array}{c}\mathrm{pH} \\
(1: 1)\end{array}$ & $\begin{array}{c}\mathrm{EC} \\
\left(\mathrm{dS} \cdot \mathrm{m}^{-1}\right)\end{array}$ & $\begin{array}{c}\text { CEC } \\
\left(\mathrm{cmol} \cdot \mathrm{kg}^{-1}\right)\end{array}$ & $\begin{array}{c}\text { OC } \\
(\%)\end{array}$ & $\begin{array}{c}\mathrm{N} \\
\left(\mathrm{mg}^{\mathrm{kg}} \mathrm{kg}^{-1}\right)\end{array}$ & $\begin{array}{c}\mathrm{P} \\
\left(\mathrm{mg}^{\mathrm{k}} \mathrm{kg}^{-1}\right)\end{array}$ \\
\hline Control & $5 / 8^{\mathrm{b}}$ & $0 / 74^{\mathrm{b}}$ & $31 / 3^{\mathrm{a}}$ & $0 / 26^{\mathrm{b}}$ & $0 / 15^{\mathrm{b}}$ & $40^{\mathrm{a}}$ \\
RHB 2\% & $8 / 11^{\mathrm{a}}$ & $0 / 9^{\mathrm{a}}$ & $31 / 6^{\mathrm{a}}$ & $0 / 51^{\mathrm{a}}$ & $0 / 38^{\mathrm{a}}$ & $33^{\mathrm{b}}$ \\
RHB 4\% & $8 / 38^{\mathrm{a}}$ & $1 / 13^{\mathrm{a}}$ & $31 / 8^{\mathrm{a}}$ & $0 / 63^{\mathrm{a}}$ & $0 / 41^{\mathrm{a}}$ & $31 / 6^{\mathrm{b}}$ \\
\hline
\end{tabular}

RHB Effect on Different Potassium Deformations: The results of Figure 1 show that soil solution potassium is affected by the addition of RHB and its surface. In general, the addition of $4 \%$ RHB improves the 5-fold increased soluble potassium. Positive and significant correlation coefficient between soluble potassium in biochar (Table 2) and soil treated with biochar can be indicate the difference in amounts of soluble potassium in Various levels of biochar. The application of $4 \%$ RHB had a significant effect on soil solubility of potassium compared to the control.

The trend of exchange of potassium in soil as a result of RHB application (Figure 1) shows that 
exchangeable potassium has significantly increased with RHB application in soil. These results are consistent with the findings of Olarieta et al. (2011) and Gaskin et al. (2010). The rate of exchangable potassium from $3.73 \mathrm{mg} / \mathrm{kg}$ in control reached to $163 \mathrm{mg} / \mathrm{kg}$ in RHB $2 \%$ and $215 \mathrm{mg} / \mathrm{kg}$ in RHB $4 \%$. There is usually a direct relationship between the amount of exchangeable potassium and the cation exchange capacity in soils (Li et al., 2016). But since the applied biochar have no effect on the cation exchange capacity of the soil, it can be concluded that this increase is due to the equilibrium relationship between potassium forms. This means that with the application of biochar to the soil, the potassium enters the soluble phase and due to the equilibrium between the soluble and exchangeable potassium, a little amount of the potassium enters in exchangeable phase. As a result, both soluble and exchangeable forms of potassium increased. Positive and significant correlation (correlation coefficient of $0.97 * *$ ) between soluble and exchangeable potassium in control soil and in treated soil with biochar can confirm the validity of this hypothesis. Also, the relationship between non-exchangeable potassium and exchangeable potassium and soluble potassium was observed $\left(0.99^{* *}\right.$ and $0.96^{* *}$, respectively), which indicates the equilibrium relations of these three forms of potassium. The non-exchangeable form of potassium, which contains the potassium that is fixed between the layers of the minerals in the soil, was also affected by the use of biochar. Application of biochar cause to increased non-exchangeable potassium from $218 \mathrm{mg} / \mathrm{kg}$ in the control sample to $313 \mathrm{mg} / \mathrm{kg}$ in a sample treated with RHB $2 \%$ and $426 \mathrm{mg} / \mathrm{kg}$ in RHB 4\%. This increase, which is due to the diffusion of soluble potassium between the layers of minerals such as illite, vermiculite and smectite and their stabilization, can cause small changes in soil minerals and the conversion of these minerals to mica (Glab et al., 2016).

The results of Haefele et al. (2011) about the effects of rice residues on alkaline elements of soil have shown that biochar increased the usability of potassium, but reduced the amount of calcium, magnesium and exchangeable sodium.

In general, adding RHB caused a significant increase in soluble potassium in soil samples. Due to the equilibrium relationships between the three forms of potassium and the sufficient time for incubation of samples (three months), potassium ions are transfered from the soil solution to exchangeable and nonexchangeable points in soil. The level of biochar produced was also affected by the increase of different potassium forms, so that RHB $4 \%$ treatment significantly increased the amount of all three potassium forms, including soluble, exchangeable and non-exchangeable, as compared to RHB $2 \%$ treatment.

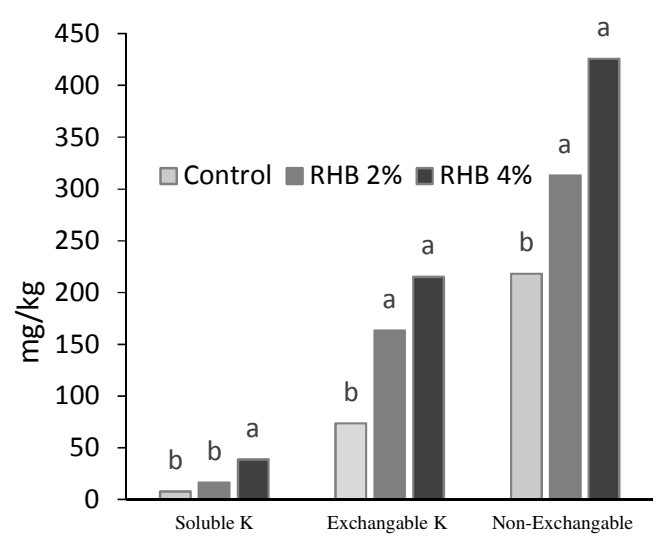

Fig 1: The impact of RHB on Different Potassium Deformations

However, the transformation of the form of potassium in the form of exchange and non-exchangeable solution of the leaching of this element, especially in coarse soils and in areas with high rainfall, increases the potassium buffer capacity of the soil and, due to its exchange with cations such as calcium, Magnesium and sodium, and sometimes the ammonium present on exchange points, can alter the composition of the ionic solution of the soil (Xu et $a l ., 2013)$. It need for further studies on the effect of biochar on the ionic composition of soil solution is suggested.

Conclusion: In general, it can be concluded that the addition of biochar causes changes in some soil properties such as electrical conductivity, $\mathrm{pH}$, and the amount of organic carbon in the soil, and the usability of some primary macroelements (especially potassium). Significant increase in the amounts of different forms of potassium, and therefore usable potassium with the application of RHB used in this study, shows that it can be used as a source of potassium in fertility management of this element in soils with potassium deficient, especially in acidic soils.

\section{REFERENCES}

Abdul, RNF; Abdul, RNS (2017). The effect of biochar application on nutrient availability of soil planted with MR219. J Microb Biochem Technol. 9: 512-519. 
Burrell, LD; Zehetner, F; Rampazzo, N; Wimmer, B; Soja, G (2016). Long-term effects of biochar on soil physical properties. Geoderma. 282: 96-102.

Carvalho, M; Madari, B; Bastiaans, L; Oort, PV; Leal, W; Heinemann, A (2016). Properties of a clay soil from 1.5 to 3.5 years after biochar application and the impact on rice yield. Geoderma. 276: 7-18.

Ding, Y; Liu, YX; Wu, WX; Shi, DZ; Yang, M; Zhong, ZK (2010). Evaluation of biochar effects on nitrogen retention and leaching in multilayered soil columns. Water, Air, \& Soil Pollution. 213(1-4):47-55.

Dong, D; Feng, Q; McGrouther, K; Yang, M; Wang, $\mathrm{H}$; Wu, W (2015). Effects of biochar amendment on rice growth and nitrogen retention in a waterlogged paddy field. $J$ Soils Sediments. 15:153-162.

Glab, T; Palmowska, J; Zaleski, T (2016). Effect of biochar application on soil hydrological properties and physical quality of sandy soil. Geoderma. 281: 11-20.

Haefele, SM; Konboon, Y; Wongboon, W; Amarante, S; Maarifat, AA; Pfeiffer, EM (2011). Effects and fate of biochar from rice residues in ricebased systems. Field Crops Res. 121(3): 430-40.

Helmke, P; Sparks, D (1996). Lithium, sodium, potassium, rubidium, and cesium. Methods of soil analysis Part 3-chemical methods (methodsofsoilan3). 551-740.

Laird, DA; Fleming, P; Davis, DD; Horton, R; Wang, BQ; Karlen, DL (2010). Impact of biochar amendments on the quality of a typical midwestern agricultural soil. Geoderma. 158: 443-449.

Li, JH; Lv, GH; Bai, WB; Liu, Q; Zhang, YC; Song, JQ (2016). Modification and use of biochar from wheat straw (triticum aestivum L.) for nitrate and phosphate removal from water. Desalin Water Treat. 57(10): 4681-4693.

Méndez, A; Gómez, A; Paz-Ferreiro, J; Gascó, G (2012). Effects of sewage sludge biochar on plant metal availability after application to a Mediterranean soil. Chemosphere. 89(11):13541359.
Mukherjee, A; Lal, R; Zimmerman, AR (2014). Impacts of biochar and other amendments on soil-carbon and nitrogen stability: A laboratory column study. Soil Sci Soc Am J. 78(4): 12581266.

Nelson, DW; Sommers, LE; Sparks, D; Page, A; Helmke, P; Loeppert, R (1996). Total carbon, organic carbon, and organic matter. Methods of soil analysis Part 3-chemical methods (methodsofsoilan3). 961-1010.

Olarieta, JR; Padrò, R; Masip, G; Rodríguez-Ochoa, R; Tello, E (2011). 'Formiguers', a historical system of soil fertilization (and biochar production?). Agr Ecosyst Environ. 140(1-2): 27-33.

Olsen, SR (1954). Estimation of available phosphorus in soils by extraction with sodium bicarbonate. United States Department of Agriculture; Washington.

Ouyang, L; Zhang, R (2013). Effects of biochars derived from different feedstocks and pyrolysis temperatures on soil physical and hydraulics properties. J Soils Sediments. 13: 1561-1572.

Rowell, DL (1994). Laboratory methods for studying mineralization. Soil science: Methods and Applications. Longman Scientific and Technical, Longman Group UK Ltd., Longman House, London, England.

Xu, G; Shao HB; Sun, JN (2013). What is more important for enhancing nutrient bioavailability with biochar application into a sandy soil: direct or indirect mechanism. Ecol Eng. 52: 119-124.

Yoo, GY; Kim, HJ; Chen, JJ; Kim YS (2014). Effects of biochar addition on nitrogen leaching and soil structure following fertilizer application to rice paddy soil. Soil Sci Soc Am J. 78: 852-860. 